\title{
Editorial
}

\section{Fault Diagnosis for Marine Propulsion System}

\author{
Xinping Yan ${ }^{*} \S$
}

School of Energy and Power Engineering, Wuhan University of Technology, Wuhan 430063, P.R. China

The purpose of the special issue is to aggregate papers on new research findings and developments in Condition Monitoring and Fault Diagnosis for Marine Propulsion Systems. Marine propulsion system is the heart of a vessel. Its normal operation ensures the security and efficiency of the trip. However, due to particular working conditions, the hull is prone to deflection and hence speeds up the degradation of the key components in the Propulsion system. A simple failure of the main diesel engine or a crack on the propeller blade may lead to malfunction of the propulsion system. Condition monitoring and fault diagnosis (CMFD) can yield an advance warning of impending failure in the system, thereby helping in maintenance and corrective

*Address correspondence to this author at the School of Energy and Power Engineering, Wuhan University of Technology, Wuhan 430063, P. R. China; Tel: +86-027-86549879; E-mail: xpyan@whut.edu actions and reducing unscheduled maintenance expenses. Therefore, this special issue may exchange recent progress in advanced techniques to improve reliability and efficiency of the health monitoring and fault diagnosis for the marine propulsion system.

The topics discussed in this special issue include: vibration analysis and oil analysis via innovative signal processing methods, new type sensors and measurement system, novel monitoring and maintenance theories, etc.

I express my sincere appreciation to all members of the Special Issue Committee and Manuscript Reviewers for their hard work to make this special issue a big success. I especially thank Professor Hanliang Xiao and Mr Zhixiong Li. I would like to thank all the authors for their contributions and support. Finally, I also thank the Publisher and Editorial staff of this journal for accepting and helping the publication of this special issue.

${ }^{\S}$ Guest Editor

(C) Xinping Yan; Licensee Bentham Open.

This is an open access article licensed under the terms of the Creative Commons Attribution Non-Commercial License (http://creativecommons.org/licenses/by-nc/3.0/) which permits unrestricted, non-commercial use, distribution and reproduction in any medium, provided the work is properly cited. 